\title{
Utilization of molecular methods to relate Red Mark Syndrome affecting Oncorhynchus mykiss to an unculturable Rickettsiales organism
}

\author{
Francesca Cecchini, Marisa Manzano*, Lucilla Iacumin, Giuseppe Comi, Donatella Volpatti, \\ Elena Galletti, Marco Galeotti \\ Dipartimento di Scienze AgroAlimentari, Ambientali e Animali, University of Udine, Italy.
}

\begin{tabular}{|c|c|}
\hline ARTICLE INFO & ABSTRACT \\
\hline $\begin{array}{l}\text { Article history: } \\
\text { Received on: } 17 / 05 / 2016 \\
\text { Accepted on: } 09 / 12 / 2016 \\
\text { Available online: } 19 / 06 / 2017\end{array}$ & $\begin{array}{l}\text { Red Mark Syndrome (RMS) is an inflammatory skin condition related to the presence of an unculturable } \\
\text { Rickettsiales organism that affects farmed rainbow trout, Oncorhynchus mykiss. This disease is responsible of } \\
\text { economic losses for fish farmers in Europe. The aim of this work was to confirm the presence of Rickettsiales } \\
\text { organisms in affected fish and to develop a specific and sensitive system that can detect the unculturable }\end{array}$ \\
\hline $\begin{array}{l}\text { Key words: } \\
\text { Rickettsiales, Red Mark } \\
\text { Syndrome, farmed rainbow trout, } \\
\text { PCR, dot blot, DNA probes. }\end{array}$ & $\begin{array}{l}\text { Rickettsiales organisms in farmed trout. Trout gathered from affected and unaffected farms were initially } \\
\text { submitted to necropsy and subsequently tissue samples were collected from each fish. Specific primers for a } \\
\text { nested PCR (RiFCfw and RiFC), and a DNA probe for dot blot assay were designed using the } 16 \mathrm{~S} \text { rRNA } \\
\text { sequence. The use of the DNA probe to target amplicons as the template increased the sensitivity to } 0.5 \mathrm{pg} / \mu 1 \\
\text { DNA. Fifteen trout were analysed, of which nine showed visible skin lesions. Eight trout out of the nine with } \\
\text { skin lesions were positive for the presence of the unculturable Rickettsiales organism DNA sequence. The } \\
\text { tests developed can help rainbow trout producers to quickly treat fish in order to reduce economic losses. Up } \\
\text { to } 30 \% \text { of fish with skin lesions are downgraded and rejected at the market by consumers. }\end{array}$ \\
\hline
\end{tabular}

\section{INTRODUCTION}

Aquaculture is a growing production system in the world, especially for high protein food. Trout is one of the most important species for EU, and rainbow trout (Oncorhynchus mykiss) is one of the most commonly cultivated trout in freshwater environments. Diseases causing multiple skin lesions can make the product less appealing to consumers, leading to product downgrade and eventual product rejection, causing economic losses for trout farmers [1, 2]. Red mark syndrome (RMS) is a disease that affects farmed rainbow trout, Oncorhynchus mykiss. It is referred by rainbow trout farmers as the biggest problem affecting the market size fish.

The disease was reported in Scotland in the winter of 2003 and has spread throughout Great Britain [3, 4] and subsequently, through continental Europe, with reports of RMS outbreaks in

* Corresponding Author

Email: marisa.manzano@ uniud.it in
Switzerland, Austria, Germany, France, and Italy [5, 6, 7, 8, 9]. Affected fish show not evident changes in behaviour or weight gain. It is not clear what predisposes fish to RMS, although stress is thought to aggravate the condition. Antibiotic treatment shortens the duration of infection, suggesting that a bacterial agent may be responsible for RMS [10]. However, many attempts to unequivocally isolate a candidate bacterial agent using conventional culture methods have been unsuccessful. Lloyd et al. $[6,10]$ found that one particular DNA sequence that is present in most strawberry disease induced lesions, the RLO 16S rDNA sequence, is also present in RMS lesions and is not present in healthy skin samples. These authors demonstrated that the organism involved was closely related to a Rickettsia spp. and was therefore referred as a Rickettsiales-like organism (RLO). Phylogenetic studies of the RLO showed that the RLO sequence is most closely related to the $16 \mathrm{~S}$ rRNA sequences of bacteria and may form a novel lineage within the order Rickettsiales [11,6]. Members of the order Rickettsiales have an obligate intracellular lifestyle, and are generally susceptible to tetracyclines [12]. 
Thus the isolation of an RLO by conventional bacteriological culture methods is very challenging. Molecular methods have frequently facilitated studies on culture-independent microorganisms in fish and most of these methods are based on direct DNA extraction from samples and a subsequent study of the 16S rRNA genes.

Fluorescent in situ hybridization (FISH) [13], denaturing gradient gel electrophoresis [14] and DNA clone libraries for the study of microbial communities have been satisfactorily used [15, 10]. Moreover, specific microorganisms can be detected with probes that anneal to specific DNA sequences [16, 10, 6, 17], and by immunohistochemistry [2].

In the present research a molecular approach and the anatomo-pathological evaluation were used to investigate RMS etiology. Symptomatic trout were collected from fish farms and subjected to necropsy in order to record and describe the macroscopic and histological lesions prior to utilise specific primers and a DNA probe in the detection of the unculturable Rickettsiales bacterium. Both PCR and dot blot assays were used in order to confirm the presence of Rickettsiales organisms, the potential aetiological agent of RMS. There are no specific preventive/therapeutic procedures able to limit the spread of RMS but it seems relevant to provide insights on the potential agent responsible for this disease.

The methods proposed in the present study might be useful for the detection of RMS at early stages so as to limit the spread of the disease and reduce economic losses in farms where trout are affected.

\section{MATERIALS AND METHODS}

\subsection{Sample collection}

Nine RMS trout of approximately $500 \mathrm{~g}$ each with skin lesions (named with the letters from A to I) were sampled from commercial farms in the North of Italy with repeated RMS outbreaks, from October 2011 to January 2012 (water temperature ranging from 9 to $10^{\circ} \mathrm{C}$ ). Six healthy trout (without skin lesions, named with the letters from L to Q) were sampled from a RMSfree fish farm and were analysed as negative controls.

\subsection{Anatomopathology}

Prior to the sampling for the bio-molecular analyses, individual fish were submitted to necropsy in order to describe the macroscopic lesions and confirm the RMS diagnosis. Then, tissue samples were collected from skin lesions and fixed in $4 \%$ neutral buffered formaldehyde. After fixation, the samples were equilibrated at RT and processed by an automatic histoprocessor (TISBE tissue processor, Diapath) to be embedded in paraffin (ParaplastPlus, Diapath). Serial $5 \mu \mathrm{m}$ sections were obtained using a programmable microtome (Reichert-Jung 2050) and stained with haematoxylin-eosin (H.E.). The specimens were examined by light microscopy (Leica DMRB) and digital images were acquired with a Nikon system. The skin macroscopic lesions were classified according to the criteria stated by Galeotti et al. [18].

\subsection{Biomolecular analysis}

The fish both showing RMS skin lesions, named from A to $\mathrm{I}$, and the healthy, named from $\mathrm{L}$ to $\mathrm{Q}$, were submitted to sampling for biomolecular analysis. Three tissue samples (one from the centre of the RMS skin lesion, one from the spleen and one from the liver), were collected separately from each individual using a sterile scalpel, and each sample was stored in a sterile plastic vial. The average weights of the collected samples were 1.5 $\mathrm{g}$ (skin), $1 \mathrm{~g}$ (spleen) and $2.5 \mathrm{~g}$ (liver). Tissue samples from skin, liver and spleen of control fish were collected with the same procedure. All the samples were maintained on ice during the sampling and were stored at $-20^{\circ} \mathrm{C}$ within a few hours until analysis.

\subsection{DNA extraction}

The DNA was extracted from the liver (liv), spleen (sp), and skin (sk) using the Wizard Genomic DNA Purification kit (Promega, Milan, Italy) following the Animal Tissue (Mouse liver and brain) protocol. Then, the DNA was stored at $-20^{\circ} \mathrm{C}$ within few hours post-sampling, until analysis. The DNA extraction for the twenty-five reference strains listed in Table 1, and used to check the specificity of the primers and the probe, was performed as described by Manzano et al. [19]. The DNAs were standardized at $100 \mathrm{ng}^{-1} \mathrm{l}^{-1}$ when used as templates in the PCR protocols.

\subsection{PCR assays for the detection of the Rickettsiales sequence}

A first PCR assay for the detection of Rickettsiales 16S rRNA in RMS-affected and unaffected tissues was performed using the RLO1 and RLO2 primers [10]. A $49 \mu 1$ aliquot of the master mix included water and contained the following reaction mixture for each sample: $1.25 \mathrm{U}$ of GoTaq® DNA Polymerase (Promega, Milan, Italy), 1X PCR buffer, $1.5 \mathrm{mmol} \mathrm{l}^{-1} \mathrm{MgCl}_{2}, 0.2$ mmol $~^{-1} \mathrm{dNTPs}$, and $0.2 \mu \mathrm{mol} \mathrm{l}^{-1}$ of each primer. The mix was distributed into each tube and $1 \mu \mathrm{l}$ of DNA $\left(250 \mathrm{ng} \mu \mathrm{l}^{-1}\right)$ was added to obtain a final volume of $50 \mu$ l. The amplification protocol was performed in a Thermal Cycler (DNA Engine Dyad Peltier Thermal Cycler, BioRad, Milan, Italy): $5 \mathrm{~min}$ denaturation at $95^{\circ} \mathrm{C}, 35$ cycles of $95^{\circ} \mathrm{C}$ for $30 \mathrm{~s}$, annealing at $69^{\circ} \mathrm{C}$ for $30 \mathrm{~s} ; 72^{\circ} \mathrm{C}$ for $30 \mathrm{~s}$; and a final extension was carried out at $72^{\circ} \mathrm{C}$ for $10 \mathrm{~min}$. The PCR assay was run on the DNA extracted from the skin, spleen, and liver tissues. Moreover, for each PCR a blank was added to ensure that the samples were uncontaminated.

Because of the unculturable nature of Rickettsiales bacterium a nested PCR (second PCR assay) was used to increase the specificity and the sensitivity of the protocol. The primer pair, RiFCfw 5'-AAGGCAACGATCTTTAGTTGG-3' and RiFC 5'CCGTCATTATCTTCCCCACT-3', were used to further amplify the amplicon obtained using the RLO1 and RLO2 primers in the first step. RiFCfw and RiFC were designed after alignment of various 16S rRNA gene sequences of microbial flora from fish, such as Candidatus Arthromitus AY007720, Enterobacter spp. HQ179966, Salmonella Enteritidis FJ465088, Vibrio spp. DQ451212, Proteus mirabilis HQ259935, Yersinia enterocolitica HM007567, Moraxella spp. HE575924, Leuconostoc lactis 
AB680284, Weissella cibaria HQ009757, Listeria monocytogenes FJ774249, Clostridium botulinum HQ328061, Escherichia coli HQ615933, Bacillus subtilis JQ309828, and Pseudomonas aeruginosa HQ712124, and uncultured Rickettsiales bacterium EU555284, AF322443 and JF421148. The software "Multiple sequence alignment with hierarchical clustering" [20] and Blast [23] were used for the purpose.

The RiFCfw and RiFC primers were first tested in silico using the AmplifX 1.5.4 [21], and then synthesized by MWGBiotech (Ebersberg, Germany) and tested for specificity on the microorganisms reported in Table 1, which were considered as negative samples (the expected amplicon was of $188 \mathrm{bp}$ ).

The concentration of the reagents used in the second PCR assay master mix was the same of first PCR assay, except the primers. One $\mu 1$ of the first PCR product was used as the template, and $1 \mu \mathrm{l}$ of sterile distilled water was used as a blank to ensure that there was no contamination. The second PCR reaction was performed in a Thermal Cycler (DNA Engine Dyad Peltier Thermal Cycler, BioRad) with the following conditions: $95^{\circ} \mathrm{C}$ denaturation for $5 \mathrm{~min}, 35$ cycles of $95^{\circ} \mathrm{C}$ for $45 \mathrm{~s}, 54^{\circ} \mathrm{C}$ for $45 \mathrm{~s}$, $72^{\circ} \mathrm{C}$ for $45 \mathrm{~s}$, and a final extension at $72^{\circ} \mathrm{C}$ for $7 \mathrm{~min}$. To evaluate the sensitivity of the second array of the nested PCR, the amplicon obtained from the amplification of the $\mathrm{E}_{\text {liv }}$ sample with the RLO1 and RLO2 primer pair was purified with the DNA Enzyme-free Isolation Spin-Kit (AppliChem, Gatersleben, Germany), measured using a NanoDrop 2000c spectrophotometer (Thermo Scientific, Wilmington, USA), and diluted to different concentrations ranging

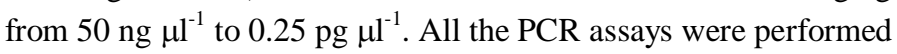
in triplicate. The amplicons were visualized by an electrophoretical separation in a $2 \%$ agarose gel (Sigma, Milan, Italy) stained with ethidium bromide $\left(0.5 \mathrm{mg} \mathrm{ml}^{-1}\right)$ in $0.5 \mathrm{X}$ TBE buffer (tris-borate-EDTA, $0.045 \mathrm{~mol} \mathrm{l}^{-1}$ Tris-borate; $0.001 \mathrm{~mol} \mathrm{l}^{-1}$ EDTA, pH 8) of $5 \mu \mathrm{l}$ aliquots, and compared with a 100 bp DNA Ladder (Promega, Milan, Italy).

\subsection{Sequencing}

Amplicons obtained from the nested PCR using the RiFCfw and RiFC primers were purified using the QIAquick PCR Purification Kit (Qiagen, Milan, Italy), dried and sent to the MWG sequencing centre (Eurofins MWG GmbH, Martinsried, Germany) for sequencing as reported by Cecchini et al. [16].

\subsection{Probe design to detect the RLO sequence}

A 63 bp probe (Rick probe) specific for unculturable Rickettsiales bacterium was designed to anneal within the sequence of the amplicon obtained by the RiFCfw and RiFC primers, and was tested for specificity using the same sequences and softwares previously reported in section 2.5 .

The sequence of the probe synthesised by MWG-Biotech (Ebersberg, Germany) and labelled at 5 ' and 3 ' ends to increase the resolution was as follows: 5'- AAT ATT GGA CAA TGG GCG CAA GCC TGA TCC AGC GAC GCC GCG TGA GTG ATG AAG GCC TTA GGG -3'. An ssDNA sequence (Anti-Rick probe) complementary to the Rick probe sequence was used as positive control in the blotting protocols to optimise the hybridisation conditions and as a positive control. The specificity of the probe was tested on the DNA extracted from the microorganisms reported in Table 1.

Table 1: List of the reference microorganisms used to test the sensitivity and specificity of the DNA probes.

\begin{tabular}{|c|c|c|}
\hline $\mathbf{N}^{\circ}$ & microorganism & source \\
\hline 1 & Aeromonas sobria 19176 & $\mathrm{DSM}^{\circ}$ \\
\hline 2 & Bacillus cereus 2301 & $\mathrm{DSM}^{\circ}$ \\
\hline 3 & Bacillus coagulans 2308 & $\mathrm{DSM}^{\circ}$ \\
\hline 4 & Bacillus subtilis 1092 & $\mathrm{DSM}^{\circ}$ \\
\hline 5 & Citrobacter freundii 15979 & $\mathrm{DSM}^{\circ}$ \\
\hline 6 & Enterobacter cloacae 30054 & $\mathrm{DSM}^{\circ}$ \\
\hline 7 & Escherichia coli & DISTAM $^{\S}$ \\
\hline 8 & Kokuria kristinae 20032 & $\mathrm{DSM}^{\circ}$ \\
\hline 9 & Lactobacillus plantarum 20174 & $\mathrm{DSM}^{\circ}$ \\
\hline 10 & Listeria monocytogenes 7644 & ATCC* \\
\hline 11 & Leuconostoc lactis 4173 & $\mathrm{CECT}^{\circ \circ}$ \\
\hline 12 & Morganella morganii & DISTAM $^{\S}$ \\
\hline 13 & Pediococcus pentosaceus 20336 & $\mathrm{DSM}^{\circ}$ \\
\hline 14 & Proteus vulgaris & DISTAM $^{\S}$ \\
\hline 15 & Pseudomonas aeruginosa & DISTAM $^{\S}$ \\
\hline 16 & Pseudomonas bremerii & DISTAM $^{\S}$ \\
\hline 17 & Pseudomonas fluorescens & DISTAM $^{\S}$ \\
\hline 18 & Pseudomonas migulae & DISTAM $^{\S}$ \\
\hline 19 & Saccharomyces cerevisiae 36024 & ATCC* \\
\hline 20 & Salmonella enterica 4883 & $\mathrm{DSM}^{\circ}$ \\
\hline 21 & Serratia marcescens 6067 & DISTAM $^{\S}$ \\
\hline 22 & Shewanella putrefaciens & $\mathrm{DSM}^{\circ}$ \\
\hline 23 & Vibrio ruber 14379 & $\mathrm{DSM}^{\circ}$ \\
\hline 24 & Weissella cibaria 14295 & $\mathrm{DSM}^{\circ}$ \\
\hline 25 & Yersinia enterocolitica & DISTAM $^{\S}$ \\
\hline
\end{tabular}

${ }^{\circ}$ Deutsche Sammlung von Mikroorganism und Zellkulturen GmbH, Braunschweigh, Germany.

${ }^{\circ}$ Colección Española de Cultivos Tipo, Valencia, Spain.

${ }^{\S}$ Dipartimento di Scienze e Tecnologie Alimentari e Microbiologiche, Milan, Italy.

*American Type Culture Collection, Manassas, VA, USA.

\section{8 dot blot assay}

The following samples were used: (a) $1 \mu \mathrm{l}$ of DNA (100 $n g \mathrm{l}^{-1}$ ) extracted from each strain reported in Table 1 (negative control for specificity); (b) $1 \mu \mathrm{l}$ of DNA (250 $\mathrm{ng}^{-1} \mathrm{l}^{-1}$ ) extracted from the tissues of the trout (DNA extraction section, 2.4); (c) $1 \mu \mathrm{l}$ of the forty-five amplicons obtained from the second step of the nested PCR, independent of whether the amplicon was visible in the agarose gel; and (d) $1 \mu \mathrm{l}$ of various dilutions (from $50 \mathrm{ng} / \mu \mathrm{l}$ to $\left.0.25 \mathrm{pg} \mathrm{l}^{-1}\right)$ of the liver of sample $\mathrm{E}\left(\mathrm{E}_{\mathrm{liv}}\right)$ amplicon obtained in the second step of the nested PCR.

One $\mu 1$ of Anti-Rick probe (100 ng $\mu 1^{-1}$ ) was added as a positive control to each blotting assay. The dsDNAs were denatured at $95^{\circ} \mathrm{C}$ for $10 \mathrm{~min}$ and the ssDNA (DNA probes) were kept at $95^{\circ} \mathrm{C}$ for $5 \mathrm{~min}$.

Then the probes were chilled in ice immediately before spotting them onto the nylon membranes and cross-linked to the air-dried membranes by UV light for $10 \mathrm{~min}$. One $\mu 1$ of the DNA samples was spotted onto the positively charged nylon membrane. 
The nucleic acids were cross-linked to the air-dried membranes by exposure to UV light for $10 \mathrm{~min}$ and subjected to hybridization as reported by Cecchini et al. [16]. For each sample the dot blot analysis was repeated three times.

\section{RESULTS}

\subsection{Anatomopathology}

Skin lesions occupying the lateral and/or ventral body areas were macroscopically detectable in 9 examined fish. The lesions displayed various shape and extension. They were single or multi-focal and were often well circumscribed (Fig.1).

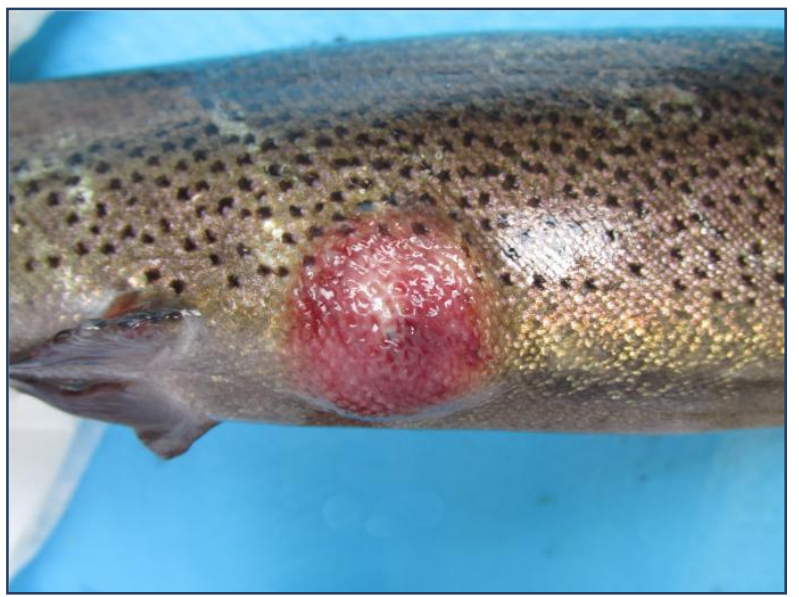

Fig. 1: Single well delimited, raised, with bright red colour RMS skin lesion in adult rainbow trout.

In few subjects they appeared as small pink spots or wider areas that were bright red in colour (Fig.1), with diameter ranging from $5 \mathrm{~mm}$ to $5 \mathrm{~cm}$. Some lesions were raised and had several levels of scale loss. In rainbow trout healthy skin, collected from a control subject, no lesions were histologically observed (Fig.2).

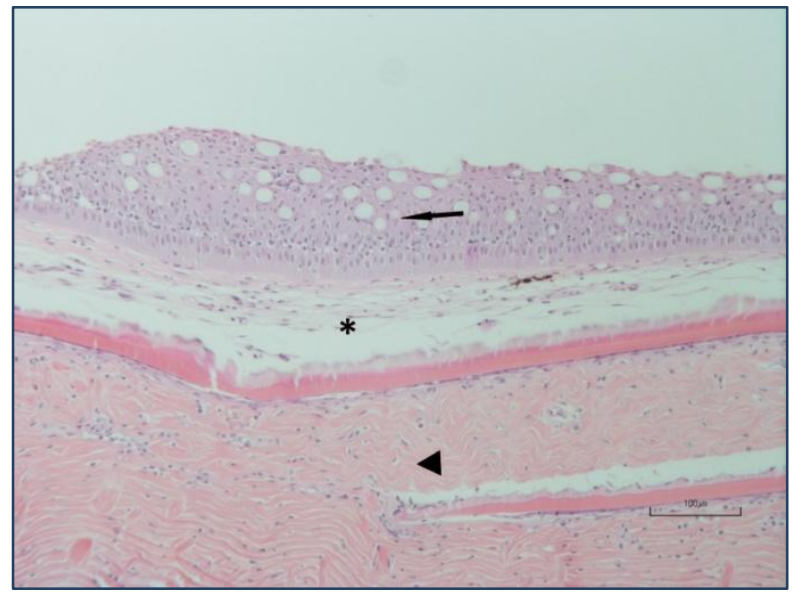

Fig. 2: Rainbow trout healthy skin, collected from a control subject. Detail of skin layers: epidermis (arrow); scale pocket (asterisk); stratum compactum of the dermis (arrow head) (H\&E).
In the skin collected from the 9 RMS affected rainbow trout, the histology revealed an inflammatory status involving all the skin layers from epidermis to subcutis (Fig.3). The epidermis was often present, or partially missing. In the stratum spongiosum of the dermis, a mild to severe lympho-monocyte infiltration could be observed (asterisk) (Fig.3).

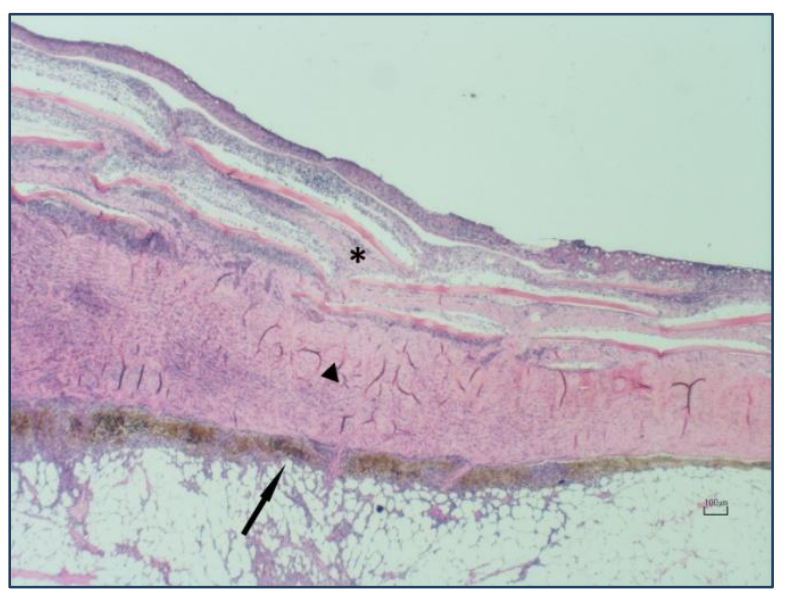

Fig. 3: Skin collected from RMS affected rainbow trout. Inflammatory condition involving all the skin layers, from epidermis to subcutis. The epidermal layer is still present. The underlying stratum spongiosum of the dermis shows scale pockets with slight oedema and cellular infiltration (asterisk). The stratum compactum appears strongly thickened and infiltrated by inflammatory cells (arrow head), invading also the subcutis (arrow) (H\&E).

The scale pockets showed a cellular infiltration and the presence of multinucleated osteoaclasts in the phase of resorption of the scales (arrow) (Fig. 4). The stratum compactum often appeared thickened and infiltrated by lymphocytes and macrophages (arrow head); the cellular infiltration involved also the subcutis (arrow) (Fig.3).

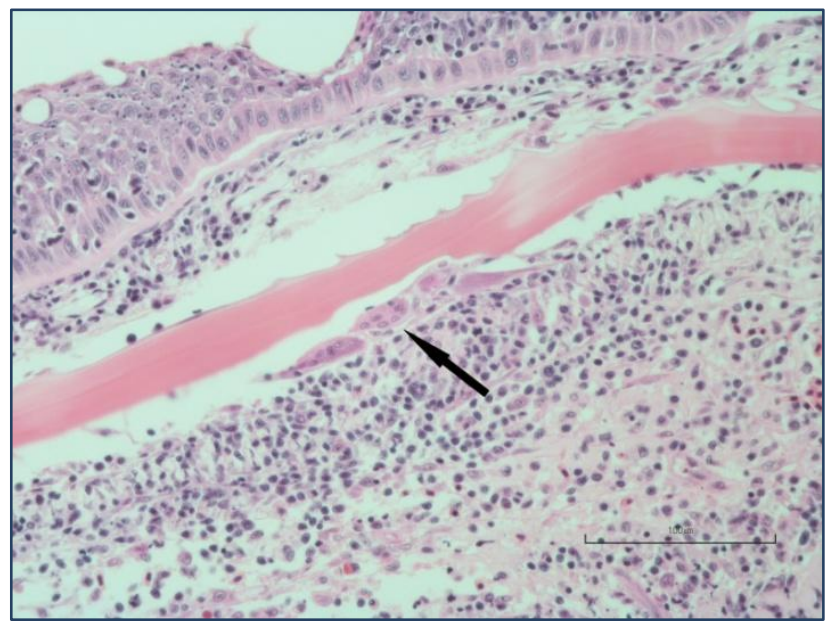

Fig. 4: Detail of Figure 3. Lymphocyte and monocyte infiltration of a scale pocket. Few multinucleated osteoaclasts in the phase of resorption of the scale (arrow).H.E. 


\subsection{PCR assay}

The RiFCfw and RiFC primers showed specificity toward unculturable Rickettsiales bacterium: no PCR products were obtained using DNA extracted from the strains listed in Table 1 , whereas the expected amplicon of $188 \mathrm{bp}$ was obtained from eight out of the nine symptomatic trout analysed (Table 2, Fig. 5). The samples I, L, M, N, O, P and Q tested negative for RLO, as no visible amplicons were produced by nested PCR. All of these samples except I were expected to be negative, as they were gathered from the site without RMS infection.

Table 2: Results of molecular assays conducted on the DNA extracted from the trout tissue samples. Trout organ description: liv= liver; $\mathrm{sp}=\mathrm{spleen;} \mathrm{sk}=$ skin. PCR: production of the amplicon by the nested-PCR using primers RiFCfw - RiFC on the DNA extracted from the tissues. Dot blot on DNA: probe hybridization on the DNA extracted from the tissues. The presence of the 188 bp amplification product, and the blue spot due to the positive hybridization reaction are indicated by: + . Absence of the $188 \mathrm{bp}$ amplification products and of the blue spot are indicated by: -. Results of samples that tested negative by using both methods in all tissues analysed (I, L, M, N O, P and Q) are not reported.

\begin{tabular}{cccccc}
\hline Sample & PCR & $\begin{array}{c}\text { Dot blot } \\
\text { on DNA }\end{array}$ & Sample & PCR & $\begin{array}{c}\text { Dot blot } \\
\text { on DNA }\end{array}$ \\
\hline $\mathrm{A}_{\text {liv }}$ & + & - & $\mathrm{E}_{\text {liv }}$ & + & - \\
$\mathrm{A}_{\mathrm{sp}}$ & + & + & $\mathrm{E}_{\mathrm{sp}}$ & + & + \\
$\mathrm{A}_{\mathrm{sk}}$ & + & + & $\mathrm{E}_{\mathrm{sk}}$ & + & - \\
$\mathrm{B}_{\mathrm{liv}}$ & - & - & $\mathrm{F}_{\text {liv }}$ & - & - \\
$\mathrm{B}_{\mathrm{sp}}$ & + & + & $\mathrm{F}_{\mathrm{sp}}$ & - & - \\
$\mathrm{B}_{\mathrm{sk}}$ & - & - & $\mathrm{F}_{\mathrm{sk}}$ & + & + \\
$\mathrm{C}_{\text {liv }}$ & - & - & $\mathrm{G}_{\mathrm{liv}}$ & - & - \\
$\mathrm{C}_{\mathrm{sp}}$ & - & - & $\mathrm{G}_{\mathrm{sp}}$ & - & - \\
$\mathrm{C}_{\mathrm{sk}}$ & + & - & $\mathrm{G}_{\mathrm{sk}}$ & + & - \\
$\mathrm{D}_{\mathrm{liv}}$ & - & - & $\mathrm{H}_{\mathrm{liv}}$ & + & - \\
$\mathrm{D}_{\mathrm{sp}}$ & + & + & $\mathrm{H}_{\mathrm{sp}}$ & - & - \\
$\mathrm{D}_{\mathrm{sk}}$ & + & + & $\mathrm{H}_{\mathrm{sk}}$ & + & - \\
\hline
\end{tabular}

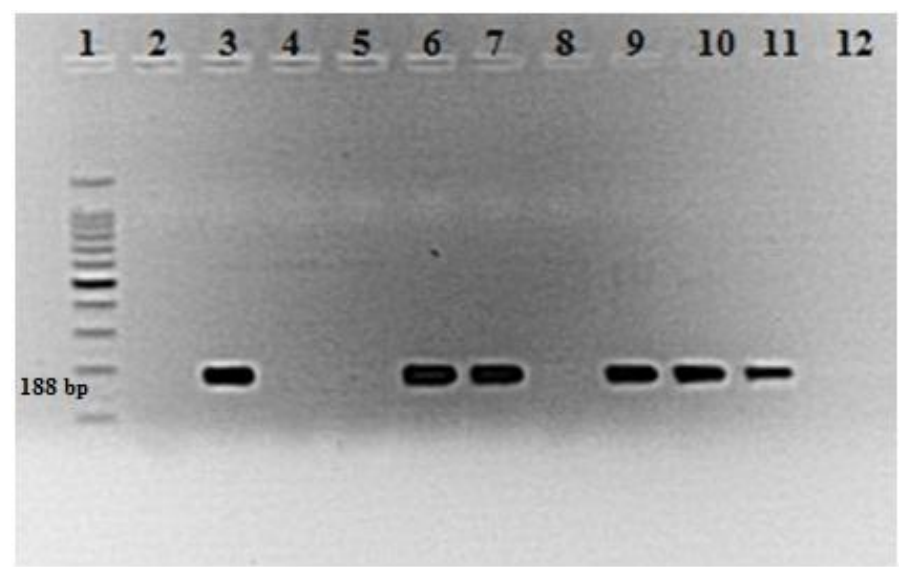

Fig. 5: Examples of PCR products obtained for liver, spleen, and skin samples from affected trout using primers RiFCfw and RiFC. Lane 1, molecular weight (100 bp, Promega); lane 2, negative control; lane 3, A spleen; lane 4, B liver; lane 5, C spleen; lane 6, D skin; lane 7, E liver; lane 8, F spleen; lane 9, G skin; lane 10, $\mathrm{H}$ liver; lane 11, H skin; lane 12, $\mathrm{H}$ spleen.

Only two subjects, A and E, resulted positive for Rickettsiales in all the three tissues analysed by PCR. The other six positive subjects, B, C, D, F, G and H, showed positivity only for one or two tissue samples. Totally 14 samples out of the 45 analysed resulted positive by PCR. Using various dilutions of the $\mathrm{E}_{\mathrm{liv}}$ amplicon obtained with the RLO1 and RLO2 primers in the first step of the nested-PCR as the template, the sensitivity of the RiFCfw and RiFC primer pair was found to be $1 \mathrm{pg}_{\mu l^{-1}} \mathrm{DNA}$ (Fig. $6)$.

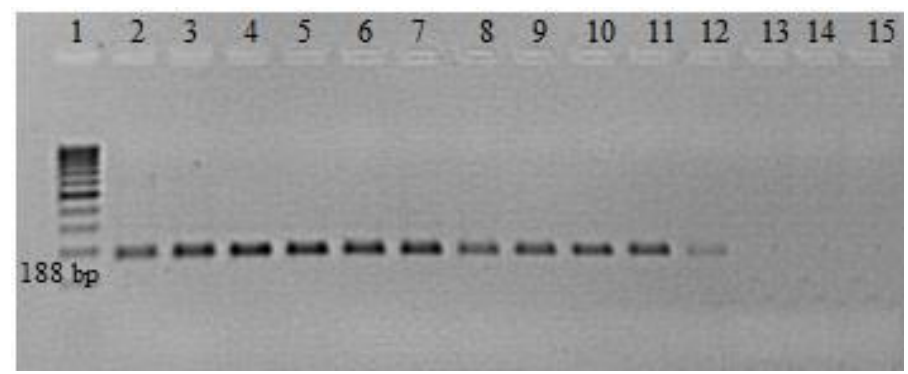

Fig. 6: Results of sensitivity of the primers RiFCfw - RiFC using as a template $1 \mu 1$ of the amplicon obtained with the RLO1-RLO2 primers at various dilutions. Lane 1: 100 bp DNA Ladder (Promega, Milan, Italy); lane 2: $1 \mu 1$

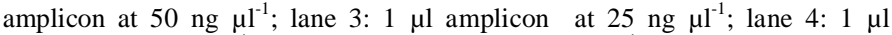

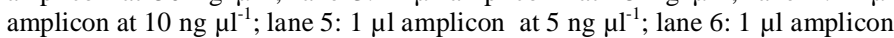
at $1 \mathrm{ng}_{\mu \mathrm{l}^{-1}}$; lane 7: $1 \mu \mathrm{l}$ amplicon at $0.5 \mathrm{ng} \mathrm{l}^{-1}$; lane 8: $1 \mu \mathrm{l}$ amplicon at $0.1 \mathrm{ng}$

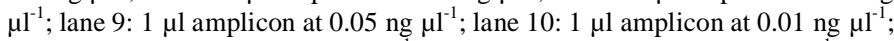

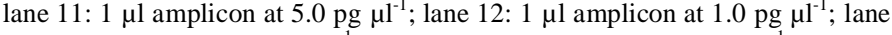
13: $1 \mu \mathrm{l}$ amplicon at $0.5 \mathrm{pg} \mathrm{l}^{-1}$; lane $14: 1 \mu \mathrm{l}$ amplicon at $0.25 \mathrm{pg}^{-1} \mathrm{l}^{-1}$; lane 15 : negative control.

\subsection{Sequencing}

The amplicons of $188 \mathrm{bp}$ obtained using the primers RiFCfw and RiFC, and reported in Fig. 5, that were sent to the MWG sequencing centre, completely matched (100\%) (Supplementary Material S1) (Fig. 7) with the uncultured Rickettsiales bacterium sequence retrieved from GenBank (EU555284). This result demonstrated that the DNA products obtained by the nested PCR belonged to an uncultured Rickettsiales bacterium.
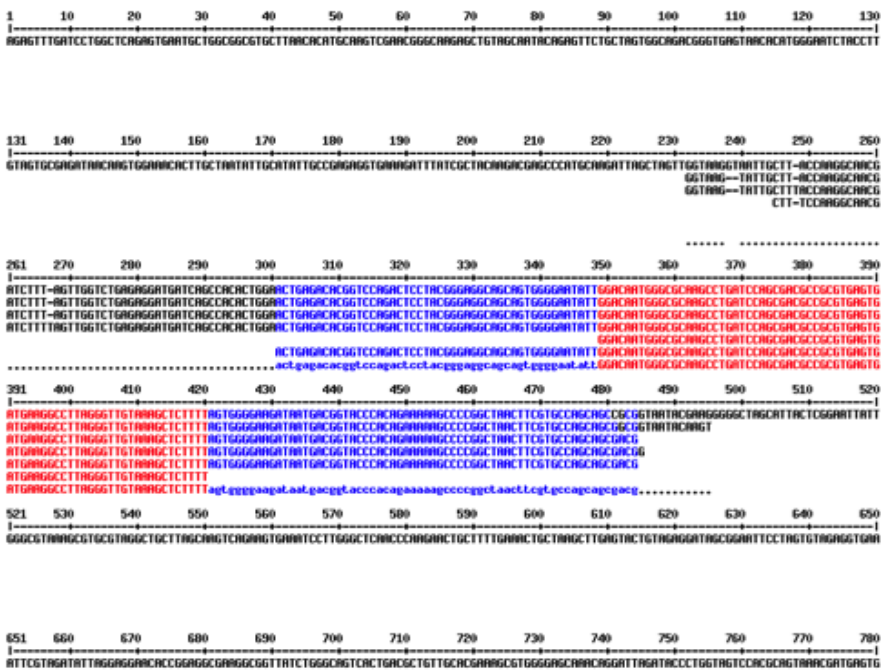

Fig. 7: Allignment of some amplicons obtained with RiFCfw-RiFC primers Row 1: Rickettsiales bacterium EU555284; row 2: sample A skin; row 3: sample A spleen; row 4: sample D spleen; row 5: sample D skin; row 6: sample G skin; row 7: consensus 


\section{4 dot blot system}

No hybridization was achieved between $10 \mathrm{pmol} \mathrm{ml}^{-1}$ of the Dig-Rick probe specific for uncultured Rickettsiales bacterium and $100 \mathrm{ng} \mu \mathrm{l}^{-1}$ DNA from the bacteria reported in Table 1 (data not shown). The sensitivity of the Dig-Rick probe was tested by hybridizing the probe to different concentrations of the amplicon obtained with nested PCR using as template DNA from the liver sample $\mathrm{E}\left(\mathrm{E}_{\text {liv }}\right)$.

Blue spots were visible from $50 \mathrm{ng} \mu \mathrm{l}^{-1}$ to $0.5 \mathrm{pg} \mu \mathrm{l}^{-1}$

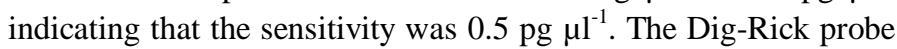
used on the DNA extracted from tissues produced seven positive samples $\left(A_{\mathrm{sp}}, \mathrm{A}_{\mathrm{sk}}, \mathrm{B}_{\mathrm{sp}}, \mathrm{D}_{\mathrm{sp}}, \mathrm{D}_{\mathrm{sk}}, \mathrm{E}_{\mathrm{sp}}, \mathrm{F}_{\mathrm{sk}}\right)$ out of forty-five analysed by dot blot (Table 2). The number of positive samples increased to twenty using the Dig-Rick probe on one $\mu$ l of each amplicon obtained with the RiFCfw and RiFC primers (Fig. 8), and confirmed the positive results obtained with the nested PCR. Moreover, six samples that tested negative in the PCR assay $\left(\mathrm{C}_{\text {liv }}\right.$, $\mathrm{E}_{\mathrm{sk}}, \mathrm{F}_{\text {liv }}, \mathrm{G}_{\mathrm{liv}}, \mathrm{G}_{\mathrm{sp}}$, and $\mathrm{H}_{\mathrm{sp}}$ ) as determined by the absence of visible amplicons on the agarose gel when electrophoresed, tested positive in the dot blot assay using the Dig-Rick probe on the amplicons (Fig. 8, spots A7, B3, B4, B7, B11). This result can be explained as: i) agarose gels are not very sensitive (they require about $10 \mathrm{ng}$ DNA to produce a clear visible band) and the labelled probe

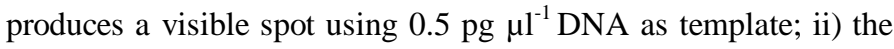
not "normal" condition of some tissues that can affect PCR, as reported by Chen et al. [22], not giving a PCR product after the first step of PCR.

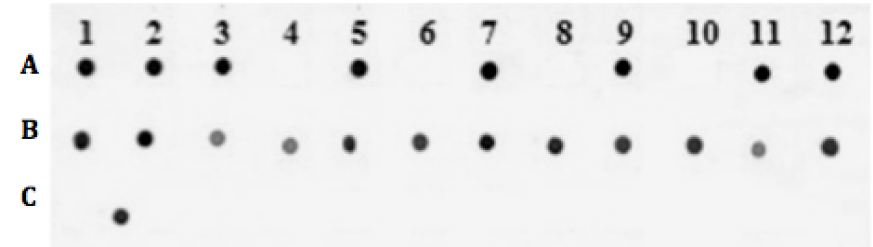

Fig. 8: Dot blot results obtained by using the Dig-Rick probe specific for RLO (at $10 \mathrm{pmol} \mathrm{ml}^{-1}$ ) on the amplicons obtained using the RiFCfw - RiFC primers; liv= liver; $\mathrm{sp}=$ spleen; $\mathrm{sk}=$ skin.

Row A, spotA1: $A_{\text {liv }}$; spot A2: $A_{\text {sp }}$; spot A3: $A_{\text {sk }}$; spot A4: B liv ; spot A5: $\mathrm{B}_{\mathrm{sp}}$; spot A6: $\mathrm{B}_{\mathrm{sk}}$; spot A7: $\mathrm{C}_{\mathrm{liv}}$; spot A8: $\mathrm{C}_{\mathrm{sp}}$; spot A9: $\mathrm{C}_{\mathrm{sk}}$; spot A10: $\mathrm{D}_{\mathrm{liv}}$; spot A11: $\mathrm{D}_{\mathrm{sp}}$; spot A12: $\mathrm{D}_{\mathrm{sk}}$;

Row B, spot B1: $\mathrm{E}_{\text {liv }}$; spot B2: $\mathrm{E}_{\mathrm{sp}}$; spot B3: $\mathrm{E}_{\mathrm{sk}}$; spot B4: $\mathrm{F}_{\text {liv }}$; spot B5: $\mathrm{F}_{\mathrm{sp}}$; spot B6: $\mathrm{F}_{\mathrm{sk}}$; spot B7: $\mathrm{G}_{\text {liv }}$; spot B8: $\mathrm{G}_{\mathrm{sp}}$; spot B9: $\mathrm{G}_{\mathrm{sk}}$; spot B10: $\mathrm{H}_{\text {liv }}$; spot B11: $\mathrm{H}_{\mathrm{sp}}$; spot B12: $\mathrm{H}_{\text {sk }}$;

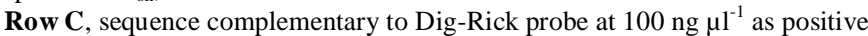
control.

\section{DISCUSSION}

Due to the anatomo-pathological findings it was possible to recognize the disease affecting rainbow trout as RMS according to the description reported by Galeotti et al., [18] and Oidtmann et al. [8]. Apart from the typical RMS lesions, the fish submitted to biomolecular analyses showed no other disease signs. As hypothesized by Lloyd et al. [10], RLO is a primary or concurrent cause of RMS in rainbow trout, thus the goal of this study was to develop a method for an early detection of specific DNA sequences related to Rickettsiales in RMS affected trout. Because of the unculturable nature of this microorganism, isolation procedures using plate counting methods are not useful in its detection [10, 6, 12]. Moreover, culturing methods for the detection of obliged intracellular bacteria, require about one month when relevant, and they are not practical for routine diagnosis.

The application of the described molecular methods, RiFCfw and RiFC primers and the labelled DNA probe, is important for the early detection of Rickettsiales in affected trout as they show high sensitivity.

The RiFCfw and RiFC primers produced a highly specific single amplicon of $188 \mathrm{bp}$, which matched $100 \%$ with the DNA sequence of the uncultured Rickettsiales bacterium present in GenBank (Supplementary Material S1) going down to a detection limit of $1 \mathrm{pg} \mu \mathrm{l}^{-1}$ of DNA, as shown in Fig. 6. This value increased the sensitivity, as it is approximately $10^{4}$ times lower than the value of $20 \mathrm{ng}^{-1} \mathrm{l}^{-1}$ reported by other authors [10] allowing for an early detection of the disease-causing agent. The negative results obtained for samples gathered from the disease-free farm (L, M, $\mathrm{N}, \mathrm{O} \mathrm{P}$ and Q) confirmed the specificity of the assay.

The presence of one subject (I) that tested negative for Rickettsiales in the molecular methods but still showed the typical skin lesions (red marks) on the flank may be justified by the assumption that the inflammatory response might persist during the regression phase of the disease even if the Rickettsiales has been eliminated by the macrophages.

The utilization of the probe on the amplicon as a template lead to the confirmation of the positive results obtained by PCR and increased the sensitivity that is $0.5 \mathrm{pg}^{-1}$ of DNA, lower than $1 \mathrm{pg} \mu \mathrm{l}^{-1}$ of DNA that the primers could detect. The assays proposed in this work are more simple and easy to use than the methods for detecting DNA sequences proposed in previous studies like cloning methods, that require the utilization of specific plasmids for competent cell transformation as well as the construction of a DNA library for sequencing [10]. Other authors used cell lines to isolate the supposed intracellular pathogen, and because these pathogens can be associated with insects hosts, insect cell lines are required [2].

The methods mentioned above are more difficult and laborious than the amplification of DNA extracted from the matrix with the RiFCfw and RiFC primers even if coupled with the dot blot as proposed in this work. The methods proposed takes about 24-30 hours to produce results including DNA extraction, PCR steps and also dot blot if added, thus we can consider this methods rapid, especially when compared to plate culture methods.

\section{CONCLUSIONS}

The PCR and dot blot assays proposed in this work can be used alone or together to decrease the detection limit, and can therefore be helpful in improving the RMS etiological diagnosis. Both methods are simple and rapid and thus they can facilitate the processing of a large number of samples in a short time. They can be used in the early diagnosis of the disease, allowing an early treatment of the farmed fish, aimed to reduce the spread of an 
infection responsible for a low rate of mortality but causing substantial economic losses for trout farmers.

\section{Financial support and sponsorship: Nil.}

Conflict of Interests: There are no conflicts of interest.

\section{REFERENCES}

1. Ferguson HW. Skin. In: Ferguson HW editors. Systemic Pathology of Fish. London, Scotian Press; 2006, p. 64-89.

2. Metselaar M, Thompson KD, Gratacap RML, Kik MJL, LaPatra SE, Lloyd SJ, Call RD, Smith PD, Adams A. Association of red-mark syndrome with a Rickettsia-like organism and its connection with strawberry disease in the USA. Journal of Fish Disase. 2010; 33:849858 .

3. Schmidt-Posthaus H, Bergmann W, Knüsel R, Heistinger H, Licek E. Appearance of red mark syndrome /cold water strawberry disease in Switzerland and Austria. Diseases of Aquatic Organisms. 2009; 88:65-68.

4. Verner-Jeffreys DW, Pond MJ, Peeler EJ, Rimmer GSE, Oidtmann B, Way K, Mewett J, Jeffrey K, Bateman K, Reese RA, Feist SW. Emergence of cold water strawberry disease of rainbow trout Oncorynchus mykiss in England and Wales: outbreak investigations and transmission studies. Diseases of Aquatic Organisms. 2008; 79:207-218

5. Galeotti M, Giavenni R, Volpatti D, Beraldo P, Feist S. Red mark syndrome/cold water strawberry disease: emergence in Italy and histopathological investigations. 15th international conference on diseases of fish and shellfish organized by the EAFP. 2011. Split, Croatia.

6. Lloyd SJ, La Patra SE, Snekvik KR, Cain KD, Call DR. Quantitative PCR demonstrates a positive correlation between a Rickettsia-like organism and severity of strawberry disease lesions in rainbow trout. Oncorhynchus mykiss (Walbaum). Journal of Fish Disease. 2011; 34:701-709.

7. McCarthy Ú, Casadei E, Wang T, Secombes CJ. Red mark syndrome in rainbow trout Oncorhynchus mykiss: Investigation of immune responses in lesions using histology, immunohistochemistry and analysis of immune gene expression. Fish \& Shellfish Immunology. 2013; 34:1119 - 1130 .

8. Oidtmann B, LaPatra SE, Verner-Jeffreys D, Pond M, Peeler EJ, Noguera EP, Bruno DW, St-Hilaire S, Schubiger CB, Snekvik K, Crumlish M, Green DM, Metselaar M, Rodger H, Schmidt-Posthaus H, Galeotti M, Feist SW. Differential characterization of emerging skin diseases of rainbow trout - a standardized approach to capturing disease characteristics and development of case definitions. Journal of Fish Disease. 2013; 36:921-937.

9. Olson DP, Beleau MH, Busch RA, Roberts S, Krieger RI. Strawberry disease in rainbow trout, Salmo gairdneri Richardson. Journal Fish Disease 1985; 8:103-111.

10. Lloyd SJ, LaPatra SE, Snekvik KR, St-Hilaire S, Cain KD, Call DR. Strawberry disease lesions in rainbow trout from southern Idaho are associated with DNA from a Rickettsia-like organism. Diseases of Aquatic Organisms. 2008; 82:111-118.

11. Dumler JS, Barbet AF, Bekker, CP, Dasch GA, Palmer GH, Ray SC, Rikihisa Y, Rurangirwa FR. Reorganization of genera in the families Rickettsiaceae and Anaplasmataceae in the order Rickettsiales: unification of some species of Ehrlichia with Anaplasma, Cowdria with Ehrlichia and Ehrlichia with Neorickettsia, descriptions of six new species combinations and designation of Ehrlichia equi and 'HGE agent' as subjective synonyms of Ehrlichia phagocytophila. International Journal Systematyc Evolutionary Microbiology. 2001; 51:2145-2165.
12. Yao DCJ, Moellering RCJr. Antibacterial agents. In: Murray PR editors, Manual of clinical microbiology, Washington DC: ASM Press; 2003, p. 1039-1073.

13. Langendijl PS, Schut F, Jansen GJ, Raangs GC, Kamphuis GR, Wilkinson $\mathrm{MH}$, Welling GW. Quantitative fluorescence in situ hybridization of Bifidobacterium spp. with genus-specific 16S rRNAtargeted probes and its application in faecal samples. Applied Environmental Microbiology. 1995; 61:3069-3075.

14. Manzano M, Iacumin L, Giusto C, Cecchini F, Patthey C, Fontanillas $\mathrm{R}$, Comi G. Utilization of denaturing gradient gel electrophoresis (DGGE) to evaluate the intestinal microbiota of brown trout Salmo trutta fario. Journal Veteterinary Science Medical Diagnostic. 2013;1: 1-6.

15. Kim DH, Brunt J, Austin B. Microbial diversity of intestinal contents and mucus in rainbow trout (Oncorhynchus mykiss). Journal Applied Microbiology. 2007;102: 1654-1664.

16. Cecchini F, Iacumin L, Fontanot M, Comi G, Manzano M. Identification of the unculturable bacteria Candidatus Arthromitus in the intestinal content of trout using dot blot and Southern blot techniques. Veterinary Microbiology 2012; 156:384-394.

17. Manzano M, Giusto C, Iacumin L, Patthey C, Cecchini F, Fontanillas R, Comi G. Nested PCR for the detection of Candidatus arthromitus in fish. FEMS Microbiology Letters. 2010; 308:35-39.

18. Galeotti M, Volpatti D, Beraldo P, Brunetti B, Galletti E, Feist SW. Red mark syndrome in rainbow trout (Oncorhynchus mykiss) farmed in Italy: anatomo-histopathological investigations. Journal of Comparative Pathology. 2013; 148:54-54.

19. Manzano M, Cocolin L, Cantoni C, Comi G. Bacillus cereus, Bacillus thuringiensis and Bacillus mycoides differentiation using a PCR-RE technique. International Journal of Food Microbiology. 2003; 81:249-254.

20. Corpet F. Multiple sequence alignment with hierarchical clustering. Nucleic Acid Research. 1988; 16:10881-10890.

21. Jullien $\mathrm{N}$. http://crn2 m.univ-mrs.fr/pub/recherche/equipe-tbrue/jullien-nicolas/programmation/amplifx/?lang=en; AmplifX 1.6.2; CNRS, Aix-Marseille Université. 2013.

22. Chen S, Fairley CK, Tabrizi SN, Quinn MA, Garland SM. Southern blot and dot blot hybridisation compared to PCR for the detection of human papillomavirus DNA in biopsies of the uterine cervix from women with dysplasia. Clinical Diagnostic Virology. 1993; 1: 187194.

23. U. S. National Library of Medicine (2014) http://blast.ncbi.nlm.nih.gov/Blast.cgi?CMD=Web\&PAGE_TYPE=B lastHome; Blast.h

\section{How to cite this article:}

Cecchini F, Manzano M, Iacumin L, Comi G, Volpatti D, Galletti E, Galeotti M. Utilization of molecular methods to relate Red Mark Syndrome affecting Oncorhynchus mykiss to anunculturable Rickettsiales organism. J App Biol Biotech. 2017; 5 (03): 001007. DOI: $10.7324 / \mathrm{JABB} .2017 .50301$ 